\title{
APPL, the Drosophila Member of the APP-Family, Exhibits Differential Trafficking and Processing in CNS Neurons
}

\author{
Laura Torroja, Liqun Luo, and Kalpana White \\ Department of Biology and Volen National Center for Complex Systems, Brandeis University, \\ Waltham, Massachusetts 02254
}

\begin{abstract}
The Drosophila Appl gene encodes a transmembrane protein that is expressed exclusively in neurons. Amino acid comparisons show that APPL protein is a member of the amyloid precursor protein (APP)-like family of proteins. Similar to mammalian APP-family proteins, APPL is synthesized as a transmembrane holoprotein and cleaved to release a large secreted amino-terminal domain. Using immunocytochemical methods, we have analyzed the distribution of APPL in the Drosophila CNS. Surprisingly, although APPL is present in all neuronal cell bodies, the neuropil shows stereotypic differential distribution. Double-labeling experiments with different neuronal markers were used to distinguish between APPL associated with neuronal processes or extracellular matrix. The distribution of APPL protein produced from transgenes encoding wild-type (APPL), secretion-defective (APPL ${ }^{\text {sd }}$ ), and constitutively secreted $\left(\mathrm{APPL}^{\mathrm{s}}\right.$ ) forms was analyzed in an Appl-deficient background to
\end{abstract}

The Drosophila APPL protein shares sequence and structural homology with the members of the amyloid precursor protein (APP) family (Rosen et al., 1989). The single mature Appl transcript is expressed exclusively in the nervous system in most, and likely all, developing and mature neurons (Luo et al., 1990; Martin-Morris and White, 1990). Mutational analysis indicates that Appl is not a vital gene (Luo et al., 1992); however, the behavioral deficits exhibited by mutant flies lacking $A p p l$ gene $\left(A p p l^{\mathrm{d}}\right)$ imply that APPL protein is necessary for the proper function of the nervous system. Transgenes encoding Drosophila APPL protein and a human neural APP isoform are able to provide similar rescue of the behavioral defects displayed by $A p p l^{\mathrm{d}}$ flies. Similarly, mice with impaired APP function are viable, yet they display functional deficits in behavioral assays (Müller et al., 1994; Zheng et al., 1995). Together with the sequence homology, these data indicate that APPL is a member of a family that is evolutionary-conserved in domain structure and function; however, the cellular processes in which these proteins engage in the nervous system remain poorly understood.

\footnotetext{
Received April 4, 1996; revised May 1, 1996; accepted May 7, 1996.

This work was supported by National Institutes of Health Grant NS29826 (K.W.) and National Institutes of Health Shared Instrumentation Grant RR05615. We are grateful to Dr. Toshiro Aigaki for generating the baculovirus APPL protein and to Drs. Toshiro Aigaki and Maryanne Fenerjian for generating the anti-APPL antibodies used in these studies. We thank Drs. H. Bellen, S. Benzer, and C. S. Goodman for providing the antibodies. We also thank Edward Dougherty for help with the artwork, and Sandhya Koushika, Hsin Chu, and Patricia Parmenter for comments on this manuscript.

Correspondence should be addressed to Kalpana White, Biology Department, Brandeis University, Waltham, MA 02254.

Dr. Luo's present address: The Howard Hughes Medical Institute, University of California, San Francisco, CA 94143.

Copyright (C) 1996 Society for Neuroscience $0270-6474 / 96 / 164638-13 \$ 05.00 / 0$
}

determine which APPL form is associated with different neuropil regions. We found that APPL ${ }^{\text {sd }}$ protein is enriched where APPL immunoreactivity coincides with neuronal processes. In contrast, $\mathrm{APPL}^{\mathrm{s}}$ preferentially localizes to those parts of the neuropil that show a diffuse APPL signal that rarely colocalizes with processes, and thus seems to be a component of the extracellular matrix. These data indicate that proteolytic cleavage and trafficking of APPL is differentially regulated in different neuronal populations. Through metamorphosis, APPL is especially abundant in growing axons and in areas where synapses are forming. Interestingly, in adult brains, APPL protein is enriched in the mushroom bodies and to a lesser extent in the central complex, structures involved in learning and memory.

Key words: amyloid precursor protein family; neuropil distribution; mushroom bodies; protein sorting and processing; mutant transgenes; Alzheimer's disease
Along with APP and APPL, the APP-family of proteins now includes two closely related genes in mammals, APLP1 and APLP2 (Wasco et al., 1992, 1993), one gene in nematodes (Daigle and Li, 1993), and one gene in Xenopus (Okado and Okamoto, 1992). APP, APLP1, APLP2, and APPL are all synthesized as membrane-spanning glycoproteins (Kang et al., 1987; Luo et al., 1990; Wasco et al., 1992, 1993), suggesting that they might serve as surface receptors. The finding that APP can associate and activate a $G_{0}$ protein through its cytoplasmic domain supports this hypothesis (Nishimoto et al., 1993; Okamoto et al., 1995). These proteins, however, undergo proteolytic cleavage that releases the large soluble ectodomain (Weidemann et al., 1989; Luo et al., 1990; Sisodia et al., 1994; Slunt et al., 1994). In vitro experiments have shown that secreted APP displays several trophic activities (Milward et al., 1992; Jin et al., 1994) and can regulate neuronal activity (Barger et al., 1995; Furukawa et al., 1996), supporting the physiological importance of the proteolytic processing.

In this study, we took an immunocytochemical approach to analyze the in vivo regulation of APPL processing and trafficking in neurons and to gain insights into the biological significance of APPL holoprotein and secreted forms. A detailed analysis of APPL distribution in the CNS in different developmental stages was performed. In addition, using transgenes encoding mutant APPL proteins that mimic the secreted form as well as the membrane-spanning form, the in vivo distribution of the transmembrane and soluble forms was examined. Specifically, we demonstrate that although synthesized in all neurons, neuronal processes and the extracellular neuropil show stereotypic differential distribution of the two APPL forms and that this distribution is dynamic during development. Furthermore, in the adult brain, 
APPL is concentrated in the mushroom bodies and to a lesser extent in the central complex, centers involved in associative learning and memory in insects. These findings suggest that transmembrane and secreted APPL forms have their respective roles and reinforce our previous finding that Appl is essential for optimal nervous system function (Luo et al., 1992).

\section{MATERIALS AND METHODS}

Fly strains. Generation of $A p p l^{\mathrm{d}}$ mutant has been described previously (Luo et al., 1992). In summary, a synthetic interstitial deletion of the central region of $\mathrm{Appl}$ gene was created by translocating a duplication containing all of the genes distal to Appl $\left(y^{+} m^{64}\right)$ to the right arm of the $\mathrm{X}$-chromosome that carried a terminal deletion that extended through Appl locus $\left(D f(1) R T^{518}\right)$. All autosomal transgenes were kept in $D f(1) w$ background.

Affinity purification of antibodies against APPL. Antiserum from rabbit 952, which was immunized with the secreted form of APPL generated in the baculovirus cells, was used for affinity purification of anti-APPL antibodies. Monospecific antibodies for APPL (Ab952M) were affinitypurified against the baculovirus-secreted APPL protein immobilized on a nitrocellulose filter, following the protocol described in Sambrook et al. (1989). The specificity of the affinity-purified anti-APPL antibody was tested by comparing Canton $S$ and $A p p l^{\mathrm{d}}$ samples in both immunoblots and immunocytochemistry.

DNA constructs for germline transformation. Caspar vector (Pirrotta, 1988 ) was used as the germline transformation vector. The three constructs used in this study (hsp:Appl $l^{+}, h s p: A p p l^{\mathrm{sd}}$, and $\left.h s p: A p p l^{\mathrm{s}}\right)$ were made using hsp70 promoter. The construction of $h s p: A p p l^{+}$and $h s p$ : $A p p l^{\text {sd }}$ has been described (Luo et al., 1990, 1992). To generate $h s p: A p p l^{\mathrm{s}}$, oligo-directed mutagenesis [with oligo ggccaccgctaatcgagctt using an oligonucleotide-directed in vitro mutagenesis system (Amersham, Arlington Heights, IL) according to the manufacturer's specification] was performed with cDNA s1 of Appl (Rosen et al., 1989) in Bluescript $\mathrm{SK}^{+}$as the template. The mutated EcoRI fragment of s1 $\left(\mathrm{Appl}^{\mathrm{s}}\right)$ was then inserted into $h s p: \mathrm{Appl}^{+}$cDNA (Luo et al., 1990), replacing the wild-type counterpart. The $h s p: \mathrm{Appl}^{\mathrm{s}} \mathrm{Xba}$ I fragment was cloned into Caspar, which had been digested with $X b a \mathrm{I}$.

P-element-mediated germline transformation was performed according to described methods (Spradling and Rubin, 1982). $D f(1) w$ flies were the parental strain for all germline transformations. Flies bearing autosomal homozygous transgenes were used for immunocytochemical analysis. Two independent insertions of each transgene were used in all of the experiments.

Heat-shock experiments. Male third-instar larvae were collected from the progeny of the cross $A p p l^{\mathrm{d}} / A p p l^{\mathrm{d}} \times D f(1) w ; h s p: A p p l^{*} / h s p: A p p l^{*}$. After a $1 \mathrm{hr}$ heat shock at $37^{\circ} \mathrm{C}$, larvae were allowed to rest at room temperature (RT) for 2 or $4 \mathrm{hr}$, and brains were dissected and immunoprocessed for confocal microscopy.

Adult males of genotype $\mathrm{Appl}^{\mathrm{d}} ; \mathrm{hsp}: \mathrm{Appl}^{*} /+$ were heat-shocked at $37^{\circ} \mathrm{C}$ for $30 \mathrm{~min}$, allowed to rest for different times, and frozen on dry ice. For each sample, the same number of frozen heads was collected into Eppendorf tubes and homogenized for immunoblotting experiments. For adult immunohistochemistry, after a resting period of $2-4 \mathrm{hr}$, heads were cut off and immediately processed for paraffin sectioning.

Protein extraction, electrophoresis, and immunoblot. Frozen heads were extracted directly in $2 \times$ SDS buffer. The sample was boiled for $3 \mathrm{~min}$ and spun in the microcentrifuge for $5 \mathrm{~min}$ before electrophoretic analysis. All protein gels were $7.5 \%$ SDS-PAGE gels with $3 \%$ stacking gels, according to standard protocols (Harlow and Lane, 1988). Bio-Rad (Richmond, CA) mini-gel (200 V, $45 \mathrm{~min})$ was used.

For immunoblotting, gels were electrotransferred onto nitrocellulose with standard procedures (Harlow and Lane, 1988) for $1 \mathrm{hr}$ at $100 \mathrm{~V}$ on ice. Immunoreaction with Ab952M (dilution 1:100) was visualized using an ECL Western blot detection system (Amersham) according to the manufacturer's specifications.

Confocal microscopy. CNSs were dissected in ice-cold PBS, fixed in $4 \%$ paraformaldehyde for $1 \mathrm{hr}$ at RT, washed six times in PBT $(0.3 \%$ Triton $\mathrm{X}-100,0.1 \% \mathrm{BSA}$, in PBS) for $15 \mathrm{~min}$ each, and incubated for $1 \mathrm{hr}$ in PBT with 5\% normal goat serum (NGS). After primary antibody incubation at $4^{\circ} \mathrm{C}$ overnight (rabbit anti-APPL antibody Ab952M; dilution 1:5), samples were washed in PBT $6 \times 15$ min and blocked with 5\% NGS. A 1:100 dilution of FITC-conjugated goat anti-rabbit secondary (Cappel) was used to incubate the sample for $4 \mathrm{hr}$ at RT (or $4^{\circ} \mathrm{C}$ overnight). Samples were washed for another $6 \times 15 \mathrm{~min}$ in PBT and mounted in $n$-propyl gallate medium or processed further for double-labeling experiments. For double-labeling, samples were then incubated with either mouse MAb $22 \mathrm{C} 10$ (dilution 1:5), mouse monoclonal anti- $\beta$-galactosidase (Promega, Madison, WI) (dilution 1:250), or mouse monoclonal anti-Fasciclin III (dilution 1:5). These antibodies were revealed with a rhodamineconjugated goat anti-mouse antibody (Jackson ImmunoResearch Laboratories, West Grove, PA) (dilution 1:100).

Confocal microscopy was performed on Bio-Rad MRC600. The CM program was used throughout. For double-labeling visualization, K1 and $\mathrm{K} 2$ filters were used.

Immunohistochemistry of sections. Cryostat sections of frozen nonfixed flies were cut, allowed to dry, and fixed for $20 \mathrm{~min}$ at RT with $4 \%$ paraformaldehyde. After $6 \times 5$ min washes with PBT, sections were incubated overnight at $4^{\circ} \mathrm{C}$ with anti-APPL antibody Ab952M diluted 1:25 in PBT. Biotinylated anti-rabbit antibody (Vector Labs, Burlingame, CA) (dilution 1:100) was used as secondary antibody, and antigenantibody complexes were detected using an HRP-conjugated avidinbiotin complex (ABC diluted 1:100; Vectastain Elite ABC Kit, Vector Labs). Signal was revealed with DAB or VIP (Vector Labs) substrates. After they were rinsed in PBS, sections were dehydrated to xylene and coverslipped.

To obtain higher signal, paraffin sections were subjected to a modified microwave antigen-retrieval protocol (Sherriff et al., 1994). Briefly, whole flies or heads were fixed in nonalcoholic Bouins overnight at $4^{\circ} \mathrm{C}$, dehydrated, and embedded in paraffin. Sections $(8 \mu \mathrm{m})$ were mounted onto glass slides, dried overnight at $42^{\circ} \mathrm{C}$, deparaffinized in xylenes, and rehydrated to water. To enhance antigen detection, all sections on slides were microwave-irradiated at full power in $\mathrm{H}_{2} \mathrm{O}$ for $10 \mathrm{~min}$, cooled to $\mathrm{RT}$, and transferred to fresh $\mathrm{H}_{2} \mathrm{O}$ for $5 \mathrm{~min}$. Sections were then washed $6 \times 5 \mathrm{~min}$ with PBT and immunoprocessed following the protocol described for frozen sections. Although this method is more sensitive and provides better morphology, the level of immunoreactive signal can vary between different experiments.

For staging pupal development, white pupae were collected and raised at $25^{\circ} \mathrm{C}$ and dissected at different intervals thereafter. Under these conditions, the adult stage is reached in $\sim 100 \mathrm{hr}$.

\section{RESULTS}

APPL protein is differentially distributed in the neuropil

APPL protein is present as a $145 \mathrm{kDa}$ transmembrane protein and a $130 \mathrm{kDa}$ soluble protein (Luo et al., 1990). The $145 \mathrm{kDa}$ holoprotein is converted to the $130 \mathrm{kDa}$ secreted form by proteolytic cleavage. An in vivo analysis of the intracellular trafficking and secretion properties of APPL in the neuronal population is informative for the following reasons. First, the biological properties of neurons in terms of APPL protein-sorting can be specific, because neurons are polarized cells where the transport of many proteins to axons and dendrites is regulated precisely. Second, the metabolism of APPL may differ between neurons, depending on their developmental and/or physiological state. Third, the secreted APPL form may localize extracellularly, and the extracellular localization may be indicative of a site of function.

To gain insights into the function and intracellular trafficking and secretion properties of APPL, we analyzed the localization of APPL protein within the different functional regions of the nervous system and at a subcellular level. The insect nervous system can be subdivided operationally into three compartments: the cortical layer where neuronal somata reside, the neuropil region where processes from the overlaying cortex and incoming fibers from other centers ramify and make synaptic contacts, and the fiber pathways that connect cortical areas to the neuropil or connect adjacent neuropil regions. The relative distribution of APPL protein in neuronal cell bodies, neuronal processes, and the extracellular matrix can be revealed by analyzing the presence of the protein in these three compartments.

To reveal APPL proteins, we used an affinity-purified polyclonal antibody generated against the amino terminal ectodomain common to both APPL forms (Ab952M; see Materials and Meth- 
ods). To test the immunocytochemical specificity of antibody Ab952M, we immunoprocessed CNSs and developing eye disks of Canton $S$ (wild type) (Fig. $1 A$ ) and $A p p l^{\mathrm{d}}$ (Fig. $1 B$ ) third-instar larvae and analyzed the preparations with confocal microscopy. As shown previously (Luo et al., 1990), in the eye disk only cells posterior to the morphogenetic furrow, where photoreceptors are differentiating, are APPL-immunoreactive. In the CNS, APPL is not detected in regions containing neuroblasts, such as the optic proliferation centers. These observations are consistent with the presence of $\mathrm{Appl}$ transcripts in postmitotic neurons (MartinMorris and White, 1990). Most neurons in the ventral ganglion $(V G)$ and the brain lobes $(B L)$ show similar levels of APPL immunoreactivity. Under the same conditions, no immunoreactive signal was detected in brains from $A p p l^{\mathrm{d}}$ larvae (Fig. 1B). Thus, all the signal revealed with Ab952M is specific to APPL proteins encoded by the Appl gene.

In the neuronal cell bodies, APPL is present in the cytoplasm and concentrated in a punctate pattern (Fig. 1C). This pattern of immunoreactivity is common to all neurons in the ventral ganglion, brain lobes, and photoreceptors, and it resembles the subcellular distribution of APP in mammalian cells (Kuentzel et al., 1993; Allinquant et al., 1994; Caporaso et al., 1994). Similar to what was observed in salivary gland cells in Drosophila (Luo et al., 1990), APPL immunoreactivity is not detected at the cell surface of the perikarya.

In contrast to the cortex where the punctate staining appeared comparable in all areas of the CNS, APPL immunoreactivity in neuropil areas was not homogeneous. Although some areas of the neuropil had undetectable levels of APPL signal, other regions were intensely stained in a reproducible way (Fig. $1 D)$. Doublelabeling experiments using anti-APPL antibody and propidium iodide, which stains nuclei, confirmed that these areas are devoid of nuclei and thus correspond to neuropil regions enriched in neuronal processes (data not shown). Neuropil regions displaying intense APPL signal, however, do not contain higher density of neuronal processes and/or synaptic contacts, as revealed by an antibody against the synaptic protein synaptotagmin (Littleton et al., 1993) or the MAb $22 \mathrm{C} 10$ that labels neuronal processes (Fujita et al., 1982) (data not shown). Figure $1 D$ illustrates APPL protein distribution in the neuropil of the CNS; in the ventral ganglion, intense APPL immunoreactivity is observed in the neuropil of the three thoracic neuromeres $(t 1, t 2$, and $t 3)$ and of the eighth abdominal neuromere ( $a 8$; inset). In the rest of the abdominal neuropil, no detectable levels of APPL protein were observed (see inset in Fig. 1D). The immunoreactivity in the intensely stained areas of the ventral ganglion neuropil seems to be qualitatively different from the punctate signal seen in cell bodies, because it has a uniform appearance. In the neuropil of the paired brain lobes, the pattern is more complex, because APPL protein seems to be concentrated in certain neuropil areas as well as along certain fiber pathways (Fig. 1D).

The presence of APPL protein in certain axons is evidenced by the strong APPL immunoreactivity associated with the photoreceptor axons in the eye stalk (es; Fig. $1 A$ ). In the CNS, the neuropil contains both axons and dendrites, making it difficult to characterize the relative distribution of APPL in these neuronal compartments. To determine whether APPL is present in dendrites, APPL immunoreactivity was analyzed in sensory neurons of the peripheral nervous system in embryos and leg imaginal disks of third-instar larvae. In these neurons, APPL immunoreactivity concentrates in cell bodies, whereas both dendrites and axons show very weak or no APPL signal (data not shown).
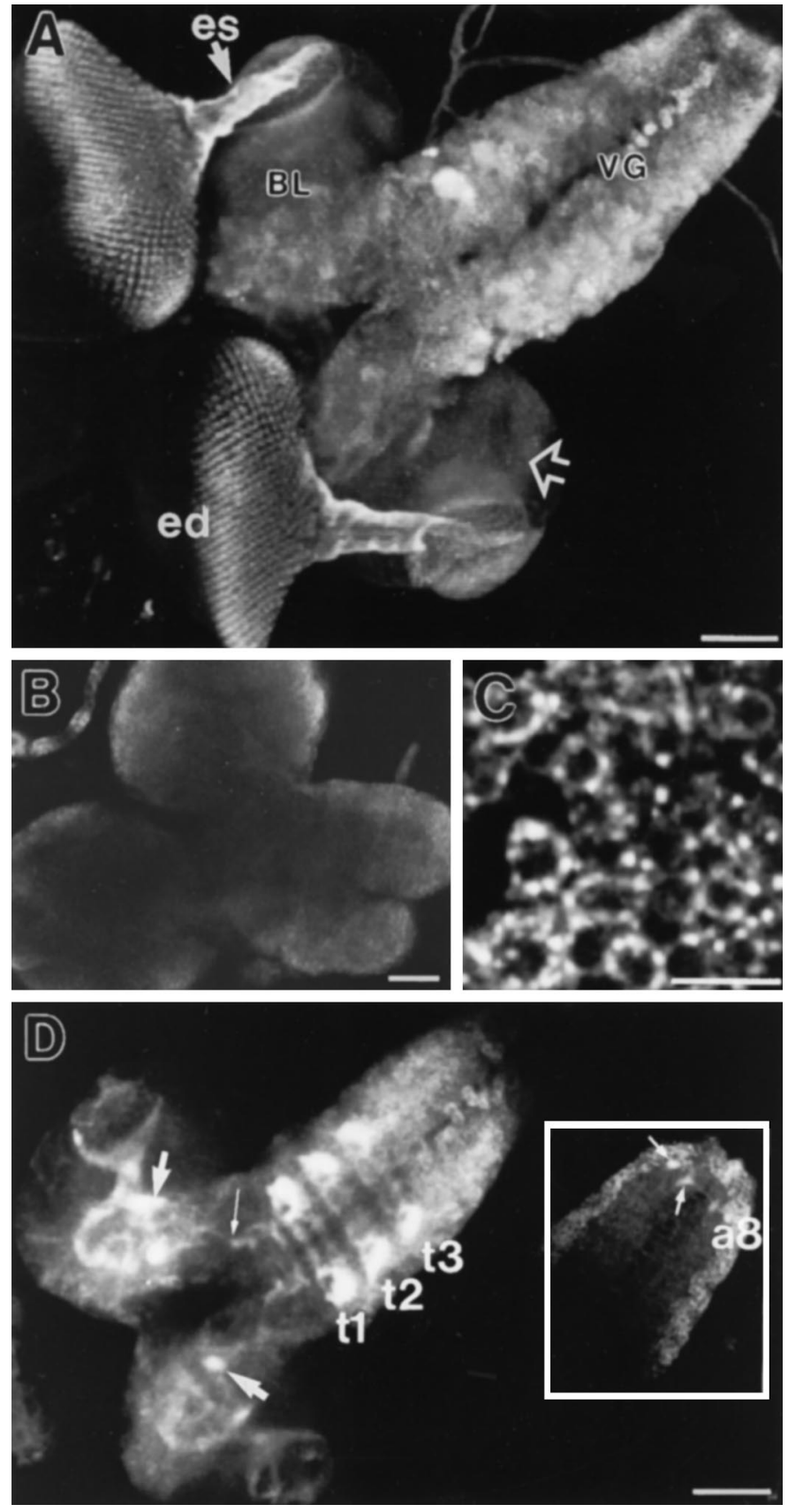

Figure 1. APPL immunoreactivity in wild-type larval CNS. $A$, An optical section of a Canton $S(C S)$ larval CNS immunolabeled with Ab952M showing APPL immunoreactivity in the neuronal cell bodies in the eye disks $(e d)$, ventral ganglion $(V G)$, and brain lobes $(B L)$. Neuroblasts in the optic proliferation centers are not APPL-immunoreactive (open arrow). Axons of photoreceptors traveling through the eye stalk (es) show intense APPL signal. $B$, An optical section through the CNS of an $A p p l^{\text {d }}$ larvae stained with Ab952M. Note the absence of APPL immunoreactivity. $C$, High magnification of APPL immunoreactivity in neuronal cell bodies of the ventral ganglion. APPL is concentrated in punctate structures surrounding nuclei. $D$, Horizontal optical section through a $C S$ larval CNS showing APPL immunoreactivity in neuropil regions. In the ventral ganglion, APPL is concentrated in the neuropil of the three thoracic neuromeres $(t 1, t 2, t 3)$. In the connection between the ventral ganglion and brain lobes, APPL is detected along axonal tracks (thin arrow). In the central neuropil of the brain lobes, APPL is concentrated in distinct areas (thick arrows). The inset shows the posterior tip of the ventral ganglion where APPL immunoreactivity is detected only in the neuropil of the eighth abdominal neuromere (a8, small arrows). Anterior is to the lower left for $A$ and $D$, and to the left for $B$. Scale bars: $A, B, D, 50 \mu \mathrm{m} ; C, 10 \mu \mathrm{m}$. 
In summary, we have shown that although APPL protein is present in most if not all neuronal cell bodies in the third-instar larval CNS, its neuropil distribution is strikingly different in different areas. In some regions, APPL signal is uniform, as in the thoracic neuropil, whereas in others, such as the optic stalk, APPL protein seems to be associated with the fiber tracks.

\section{Different APPL forms contribute to APPL immunoreactivity in different areas of the neuropil}

We were interested in analyzing whether APPL immunoreactivity detected in the neuropil centers was associated with neuronal fibers or with the extracellular matrix. Both possibilities are plausible, because APPL holoprotein is membrane-associated and can be cleaved to yield a secreted form. To answer this question, we double-labeled third-instar larval CNS with Ab952M and antibodies against the following markers for neuronal processes: an epitope recognized by the antibody MAb 22C10 (Fujita et al., $1982)$; the cytoplasmic $\beta$-galactosidase protein expressed under the pan-neural elav promoter (Luo et al., 1994); and the membrane protein Fasciclin III (Patel et al., 1987). Figure 2 shows two examples of larval brains immunoreacted with Ab952M (green) and MAb 22C10 (red). Similar results were observed when neuronal processes were labeled with anti- $\beta$-galactosidase or antiFasciclin III antibodies (data not shown). Based on the degree of association between APPL protein and neuronal processes, we found two opposite situations. In the neuropil of the thoracic neuromeres (Fig. $2 E$ ) and in some regions of the central neuropil of brain lobes (Fig. $2 B$ ), APPL protein rarely colocalizes with the neuronal markers used in this study. In some of these regions, as is evidenced in Figure $2 B$ (white arrow), APPL immunoreactivity seems to girdle processes. On the other hand, in the eye stalk (open arrow; Fig. $2 B$ ) and in the developing neuropil of the optic lobes (Fig. 2D), APPL immunoreactivity is closely associated with processes.

APPL protein associated with neuronal processes might correspond to the membrane-bound holoprotein, whereas APPL that is not associated with processes might be the secreted ectodomain. To analyze how the different forms of APPL protein contribute to APPL immunoreactivity, we made use of transgenic flies that express wild-type APPL or mutant APPL proteins, which mimic the membrane-bound or the secreted forms, in an $A p p l^{\mathrm{d}}$ genetic background. First we studied the heat-shock response of the hsp: $\mathrm{Appl}^{+}$transgene (Luo et al., 1992) by heat-shocking adult flies for $30 \mathrm{~min}$ and examining the APPL proteins by immunoblot analysis after specified intervals (Fig. $3 A$ ). Maximum levels of protein are reached $4 \mathrm{hr}$ after the heat shock. Two forms of $\mathrm{APPL}^{+}$protein are generated that show a precursor-product relationship and correspond to the membrane-bound holoprotein $(145 \mathrm{kDa})$ and the secreted $(130 \mathrm{kDa})$ forms. Therefore, consistent with what has been shown previously in S2 cells (Luo et al., 1990), in vivo processing of $\mathrm{APPL}^{+}$protein produced from the heat-shock transgene is similar to the processing of endogenous APPL protein. On the contrary, mutant $A p p l^{\mathrm{d}}$ flies carrying the hsp:Appl ${ }^{\text {sd }}$ transgene (Luo et al., 1992) express a single form of APPL (Fig. $3 C$ ) and are unable to generate a secreted protein. The $h s p: A p p l^{\mathrm{s}}$ transgene contains a mutated $A p p l$ cDNA, in which codon ${ }^{789} \mathrm{GAA}$ has been changed to generate a translation-stop TAA, so that the encoded protein lacks the transmembrane and cytoplasmic domains (see Materials and Methods). Flies carrying this construct in an $A p p l^{\mathrm{d}}$ background express only a secreted APPL protein (Fig. 3B). The overall kinetics of expression of $\mathrm{APPL}^{\mathrm{sd}}$ and $\mathrm{APPL}^{\mathrm{s}}$ is similar to that of the $\mathrm{APPL}^{+}$proteins when they are expressed under the influence of heat-shock promoter (Fig. 3A-C).

We compared APPL immunoreactivity in Canton $S$ brains and in brains from $A_{p p l} l^{\mathrm{d}}$ larvae carrying $h s p: A p p l^{+}, h s p: A p p l^{\mathrm{sd}}$, or $h s p: A p p l^{\mathrm{s}}$ transgenes. The antibody Ab952M was used, and larval CNSs were fixed and immunoprocessed 2-4 hr after the heat shock. These preparations were analyzed with confocal microscopy, and the APPL immunoreactivity was compared in the cortex, in the thoracic neuropil, and in the optic lobe neuropil.

Because the differential distribution of APPL in the neuropil could be a consequence of cell-specific differences in the levels of Appl transcription, we first proceeded to characterize APPL immunoreactivity generated from the $h s p: \mathrm{Appl}^{+}$transgene. Under these conditions, APPL protein should be produced at similar levels in all neurons, because the heat-shock response is expected to be the same in nearly all cells (Bonner and Pardue, 1976; Lis et al., 1983). In general, APPL immunoreactivity in heat-shocked transgenic brains is lower than in the wild-type brain. In the cortex, neuronal cell bodies show a punctate APPL immunoreactivity (Fig. $4 C$ ). In the ventral ganglion, APPL signal in the cortex is quite uniform (Fig. 4D), and although some cells show slightly higher levels of protein, the position of these cells varies from sample to sample and does not correlate with the pattern of immunoreactivity observed in the neuropil. APPL immunoreactivity in the neuropil, however, resembles the pattern observed in wild-type larval CNS, in both the ventral ganglion (Fig. 4A,B) and brain lobes (data not shown). As in the wild type, only the neuropil regions of the three thoracic neuromeres and the eighth abdominal neuromere display positive immunoreactivity (arrowheads, Fig. 4A,B). Thus, in a situation where all neurons produce similar amounts of APPL protein, APPL immunoreactivity in the neuropil still mimics the normal pattern, suggesting that APPL trafficking varies between different neuronal cell types and results in differential distribution of this protein in the neuropil.

Mutant APPL proteins are detected in cell bodies at levels similar to the induced wild-type protein, and they display the characteristic punctate aspect (data not shown); however, in the neuropil the two mutant forms behave differently. In the thoracic neuropil, induced $\mathrm{APPL}^{\mathrm{s}}$ protein showed a distribution similar to the induced wild-type APPL protein (compare Fig. 5, $A$ and $B$ ). In contrast, APPL ${ }^{\text {sd }}$ induction results in a very low signal in the thoracic neuropil (Fig. 5C), and the residual immunoreactive signal frequently is found along axonal tracts (not shown). The situation in the optic lobe is converse to that in the thoracic and central brain neuropils (Fig. 5D-F). Although induced wild-type APPL and secretion-defective APPL ${ }^{\text {sd }}$ proteins show enrichment in this structure at levels similar to endogenous APPL, the APPL form is found at very low levels.

In summary, these results show that those regions where APPL seems to be associated with neuronal processes (optic lobes) are the regions where secretion-defective $\mathrm{APPL}^{\text {sd }}$ is enriched. Secreted $\mathrm{APPL}^{\mathrm{s}}$, however, concentrates in regions that are rich in the APPL form that is not associated with processes (thoracic neuromeres). These data suggest that APPL is secreted in some areas of the neuropil, whereas in others it remains as a transmembrane protein, indicating that the proteolytic processing of APPL is differentially regulated.

\section{APPL distribution in the neuropil is developmentally regulated}

The results obtained so far strongly suggest that trafficking and processing of APPL protein is regulated precisely. These differ- 

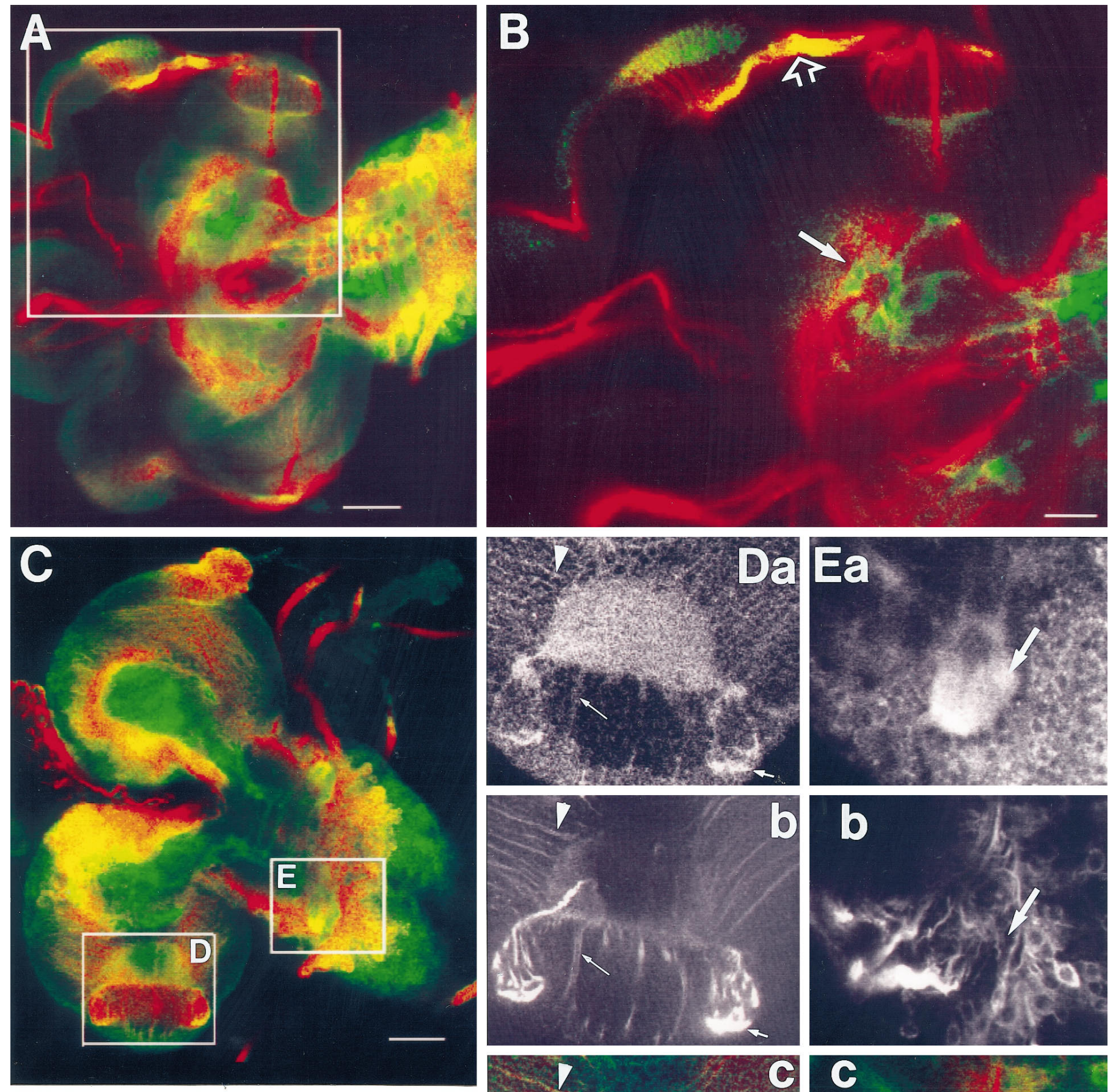

Figure 2. Localization of APPL relative to neuronal processes labeled with MAb 22C10. A, Larval CNS stained with anti-APPL (green) and 22C10 (red) antibodies. Boxed area including eye disk and brain lobe is shown at a higher magnification in $B . B$, In the eye stalk, APPL immunoreactivity colocalizes with $22 \mathrm{C} 10$ epitope, as revealed by the yellow color (open arrow). In the central neuropil of the brain lobe, APPL seems to be surrounding neuronal processes (white arrow). C, Optical section of a larval CNS stained with anti-APPL (green) and 22C10 (red) antibodies. Two boxed areas, comprising the optic lobe $(D)$ in the brain lobe and the second thoracic neuromere $(E)$ in the ventral ganglion, are shown at higher magnification in $D$ and $E$, respec-
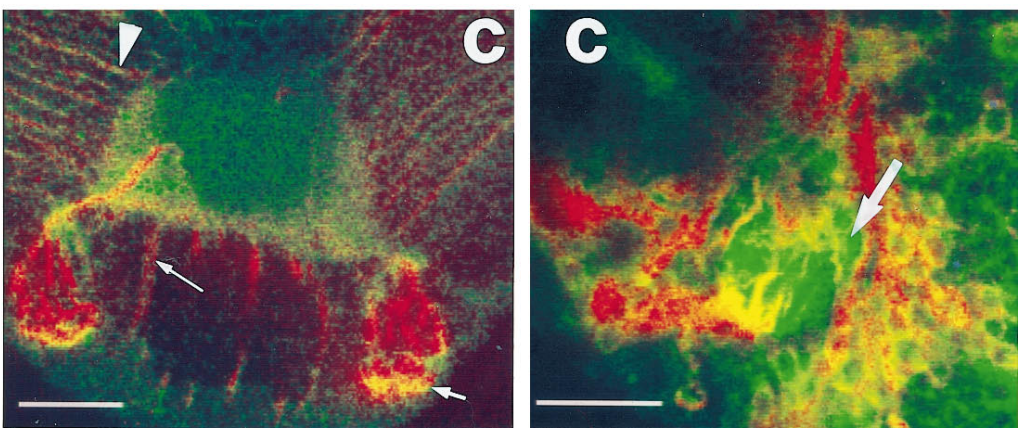

tively. $D$, A section through the larval optic lobe stained with anti-APPL antibody $(a)$, MAb 22C10 $(b)$, and both antibodies $(c)$. The central semicircular region stained with APPL corresponds to the neuropil of the medulla. Photoreceptor axons are intensely stained with both antibodies (small arrow). The thin arrow points to thick neuronal processes weakly stained with both antibodies. Thin fibers that run over the surface of the optic lobe are 22C10-immunoreactive and show APPL immunoreactivity concentrated in varicosities (arrowhead). E, A section through the second thoracic neuromere labeled with anti-APPL $(a), 22 \mathrm{C} 10(b)$, and both $(c)$. Notice that APPL immunoreactivity in this neuropil is not associated with 22C10-immunoreactive processes (arrow). In $A-E$, anterior is to the left. Scale bars: $A, C, 50 \mu \mathrm{m} ; B, D, E, 25 \mu \mathrm{m}$. 


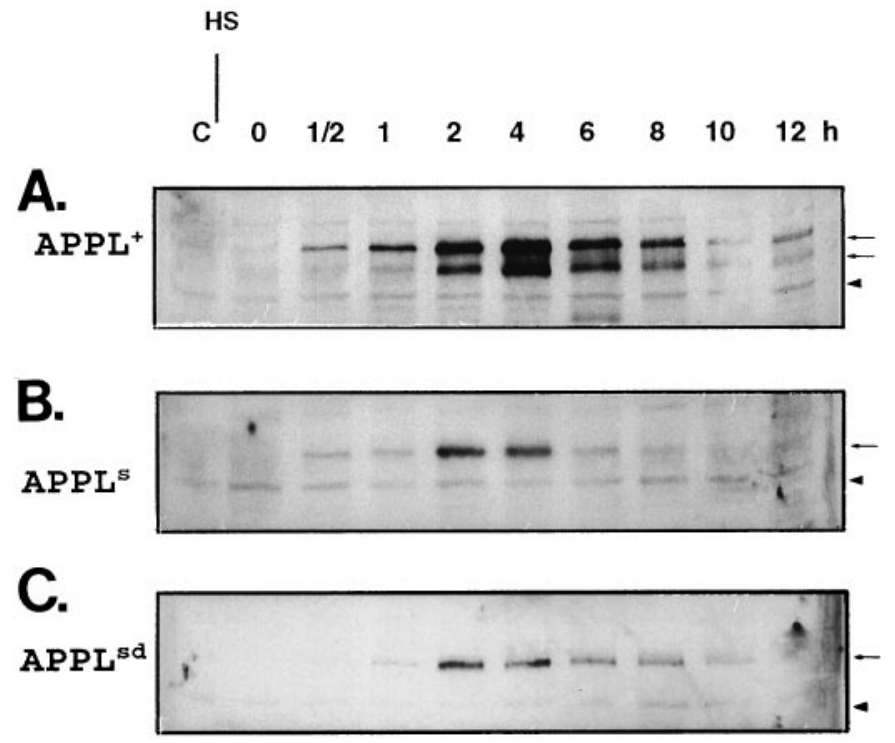

Figure 3. Induction of $h s p: \mathrm{Appl}^{*}$ transgenes. Immunoblot of head protein extracts probed with APPL-antibody. Adults were heat-shocked for $30 \mathrm{~min}$ at $37^{\circ} \mathrm{C}$; protein extracts were made from fly heads at $0,0.5,1,2,4,6,8$, 10 , and $12 \mathrm{hr}$ after the heat shock. Control extracts from flies before heat shock are loaded in the lane marked C. $A, A p p l^{\mathrm{d}} ; h s p: A p p l^{+} /+; B, A p p l^{\mathrm{d}}$; hsp: $A p p l^{\mathrm{s}} /+; C, A p p l^{\mathrm{d}} ;$ hsp:Appl ${ }^{\mathrm{sd}} /+$. Same number of heads were homogenized and loaded in each lane. Thin arrows point to APPL bands. Arrowheads point to a cross-reactive band, present also before induction.

ences could be ascribed to the physiological or developmental stage of a specific neuronal population. To gain insights into the biological significance of the regulation of APPL metabolism, we analyzed the distribution of APPL protein during metamorphosis, when the nervous system undergoes dramatic changes, in two regions: the ventral ganglion and the optic lobes. For this study we used both whole-mount preparations and paraffin or cryostat sections stained with anti-APPL antibody Ab952M.

We chose the ventral ganglion as a model to study developmental changes during metamorphosis in APPL distribution because of the simplicity of the pattern of APPL immunoreactivity observed and because the process of remodeling that occurs during metamorphosis has been well characterized in this structure (for review, see Truman et al., 1993). We have previously observed APPL along the axon tracks in the longitudinal and transverse commissures of the ventral cord in the embryo (Luo et al., 1990). In the ventral ganglion of third-instar larval CNS, APPL is no longer discerned along the longitudinal commissures but is concentrated in certain areas of the neuropil (Fig. 1D). During the first $24 \mathrm{hr}$ of metamorphosis, axons and dendrites of larval neurons prune back, and new arborizations are formed. Axonal growth from new adult-specific neurons and from preexisting larval neurons starts at $\sim 24 \mathrm{hr}$ after pupariation and is completed by $72 \mathrm{hr}$. Figure 6 illustrates how APPL immunoreactivity changes during the metamorphosis of the ventral ganglion. Immediately after pupariation (Fig. 6A), APPL distribution in the ventral ganglion resembles that described for the third-instar larval CNS. The most noticeable changes occur during the early stages of metamorphosis. Six hours after pupariation, the neuropil of the thoracic segments shows reduced APPL immunoreactivity compared with the third-instar larval CNS (Fig. 6B). By $12 \mathrm{hr}$ after pupariation, APPL-immunoreactive signal in the thoracic neuropil is lower and comparable to that in the abdominal segments
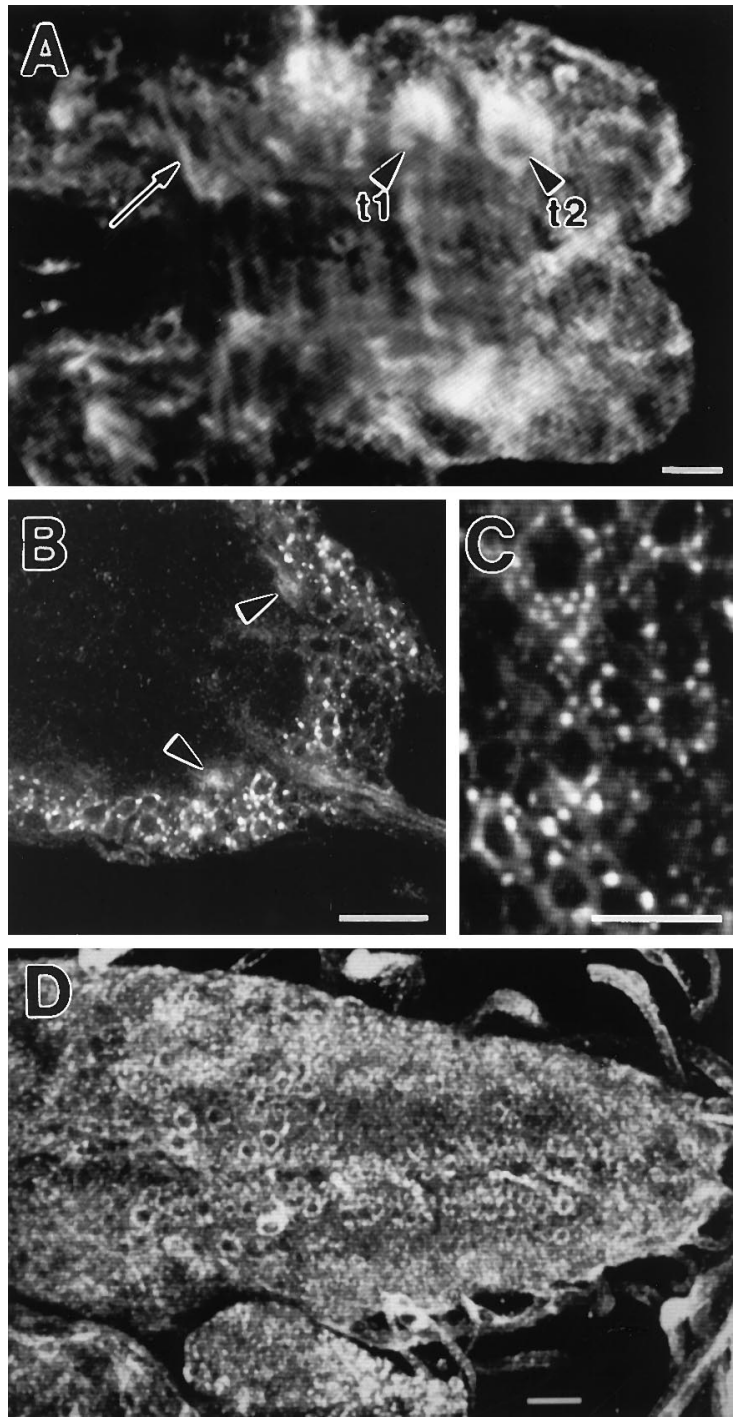

Figure 4. Localization of the $\mathrm{APPL}^{+}$protein product of the induced $h s p: \mathrm{Appl}^{+}$transgene. Third-instar larvae of genotype $\mathrm{Appl}^{\mathrm{d}}$; $h s p: \mathrm{Appl}^{+} /+$ were subjected to heat shock at $37^{\circ} \mathrm{C}$ for $1 \mathrm{hr}$, allowed to rest for $4 \mathrm{hr}$, and immunoprocessed as described (see Materials and Methods). A, Horizontal optical section through a CNS showing APPL distribution in the neuropil of the ventral ganglion: APPL is concentrated in the neuropil of the thoracic neuromeres $(t 1, t 2)$; APPL is also found along axonal tracts connecting the ventral ganglion and the brain lobes (arrow). Compare with Figure $1 D$. B, Detail of APPL protein detected in the neuropil (arrowheads) of the eighth abdominal neuromere. Compare with Figure $1 D$, inset. $C$, High magnification of APPL vesicle-like signal observed in neuronal cell bodies. Compare with Figure 1C. D, Z-series projection of horizontal optical sections through the ventral ganglion, exemplifying the uniform APPL staining observed in the cortex of the heat-shocked larval CNS. In $A, B$, and $D$, anterior is to the left. Scale bars: $A, B, D, 25 \mu \mathrm{m}$; $C, 10 \mu \mathrm{m}$.

(Fig. 6C). By $48 \mathrm{hr}$, levels of APPL protein in the neuropil are very low, and isolated immunoreactive varicosities and processes are clearly distinguishable (Fig. 6D). This pattern of APPL immunoreactivity remains unchanged until adult stages (data not shown).

Most of the neurons that form the optic lobes are new adultspecific neurons. Differentiation of these neurons progresses during late larval and pupal stages and has been well characterized (for review, see Meinertzhagen and Hanson, 1993). The first half of metamorphosis is characterized by axonal growth, whereas in 
APPL+
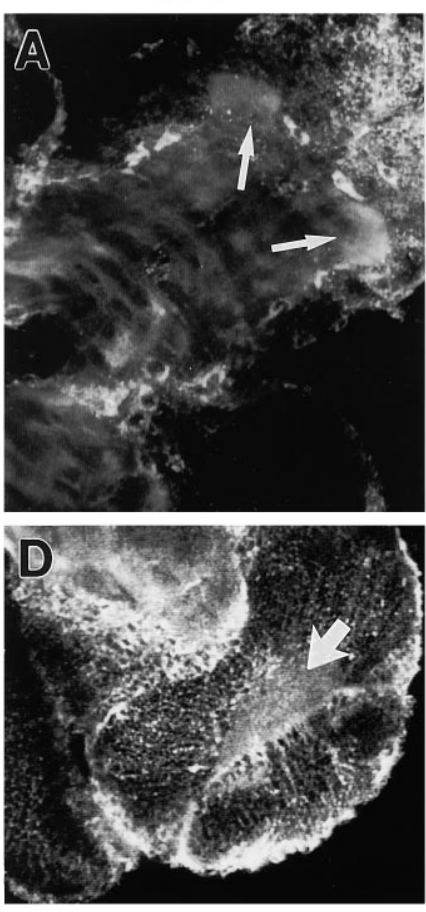

APPLS
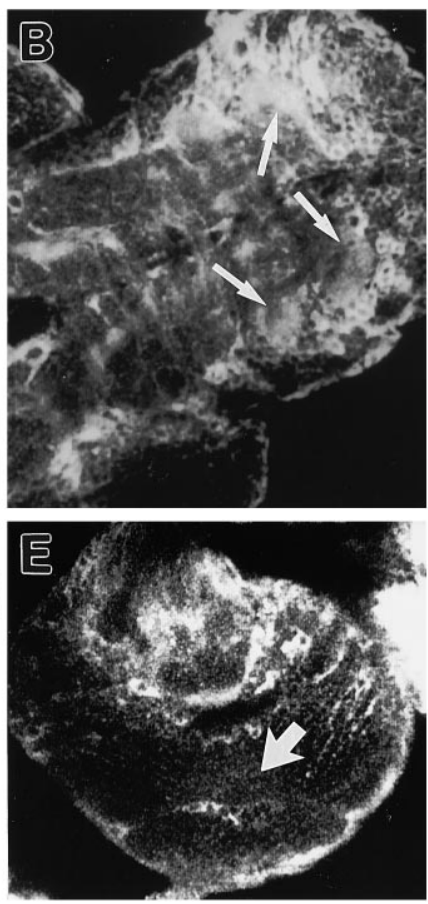

APPLSd
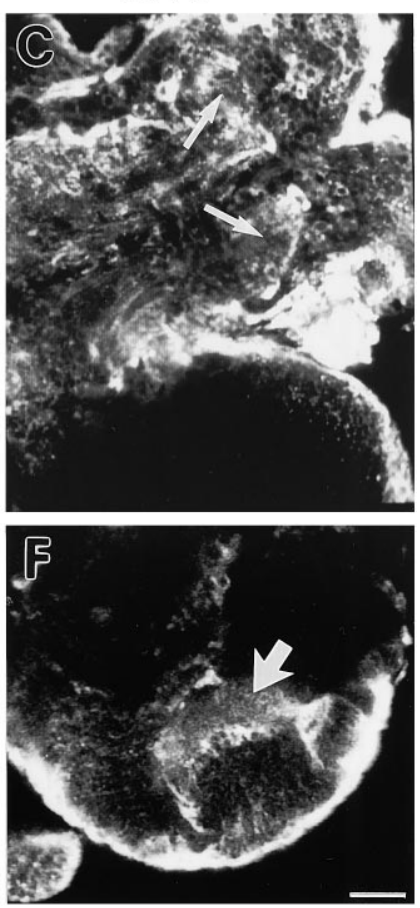
Same magnification for $A-F$. Scale bar (shown in $F$ ): $25 \mu \mathrm{m}$.

Figure 5. Localization of APPL mutant proteins in larval CNS. Larval CNS of genotypes $(A, D) A p p l^{\text {d } ; ~} h s p: A p p l^{+} /+,(B, E)$ $A p p l{ }^{\mathrm{l}}$; $h s p: A p p l^{\mathrm{s}} /+$, and $(C, F) A p p l^{\mathrm{d}}$; $h s p$ : $\mathrm{hr}$, allowed to rest for $4 \mathrm{hr}$, and immunoprocessed with anti-APPL antibody. $A-C$, A detail of APPL immunoreactivity in the thoracic neuromeres in the ventral ganglion showing how $\mathrm{APPL}^{+}(A)$ and $\mathrm{APPL}^{\mathrm{s}}$ $(B)$ proteins are concentrated in this neunot $(C) . D-F$, A detail of APPL immunoreactivity in the optic lobe is shown. Although $\mathrm{APPL}^{+}(D)$ and $\mathrm{APPL}^{\text {sd }}(F)$ proteins are found in the optic neuropil (big arrow; see Fig. $4 D$ for endogenous APPL signal), APPL $^{\mathrm{s}}$ protein $(E)$ is not detected in this region. Anterior is to the lower left. the second half, synapses are formed. The process of synaptogenesis seems to continue into the adult. Thus, the optic lobe provides a well-studied structure for correlating APPL metabolism and neuronal differentiation. Figure 7 shows APPL immunoreactivity in a section of the optic lobe in three pupal stages and in the adult. At $0 \mathrm{hr}$ after pupariation (Fig. 7A), APPL protein is concentrated in photoreceptor axons within the eye stalk and in the three
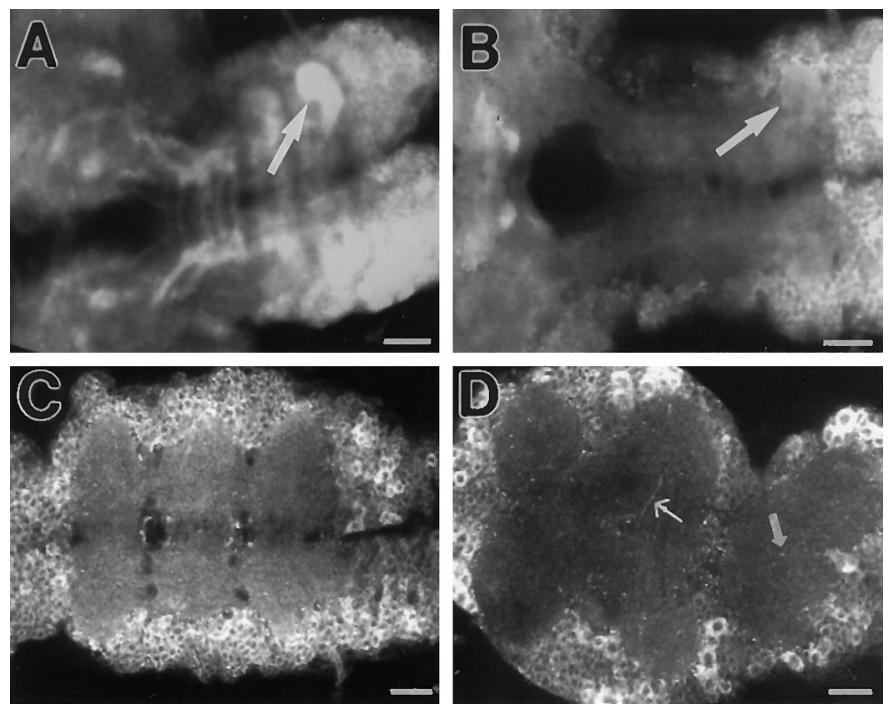

Figure 6. APPL immunoreactivity in the ventral ganglion during metamorphosis. Optical section through whole-mount preparations of ventral ganglions dissected from Canton $S$ pupae at $0 \mathrm{hr}(A), 6 \mathrm{hr}(B), 12 \mathrm{hr}(C)$, and $48 \mathrm{hr}(D)$ after pupariation and stained with anti-APPL antibody. Signal in the thoracic neuromere (arrow in $A$ and $B$ ) decreases after $6 \mathrm{hr}$, and by $12 \mathrm{hr}$ APPL is distributed evenly in the neuropil of the ventral ganglion $(C)$. By $48 \mathrm{hr}$, the level of APPL in the neuropil is low, and distinct processes (thin arrow) and varicosities (small arrow) are revealed. For $A-D$, anterior is to the left. Scale bars: $A-D, 25 \mu \mathrm{m}$. neuropils of the optic lobe: lamina $(l)$, medulla $(m)$, and lobula complex (loc). During development, the optic lobe rotates dorsally, and the relative position of the optic neuropils changes. By $25 \mathrm{hr}$, APPL signal in the optic neuropils remains intense (Fig. $7 B)$. Sixty hours after pupariation, APPL immunoreactivity in the medulla is arranged in a modular distribution in three layers (Fig. $7 C$ ) that are reminiscent of the synaptic layers described in the adult medulla (Bausenwein and Fischbach, 1992; Bausenwein et al., 1992). APPL staining in the lamina becomes more intense, and axons are distinguished clearly (Fig. $7 C$ ). In the adult (Fig. 7D), intense APPL immunoreactivity remains in the lamina neuropil. APPL signal in the medulla and lobula neuropils is very low and comparable with the rest of the brain neuropil, except for some isolated axonal processes observed in the medulla.

We have seen that during metamorphosis, the pattern of APPL immunoreactivity in the neuropil of the nervous system displays dynamic changes. In the ventral ganglion, these changes coincide with the period of axon retraction and outgrowth. During the major period of synaptogenesis in the optic lobes, the APPL immunoreactivity pattern in the neuropil resembles the distribution of the synaptic layers.

\section{In the adult, APPL is concentrated in the mushroom bodies}

Larval CNS contains both fully differentiated and developing neurons, whereas pupal CNS is composed essentially of developing neurons. We wanted to study APPL distribution in adult brains, where all neurons are physiologically mature. APPL immunoreactivity was analyzed in frozen and paraffin sections of adult CNS. The cell bodies of adult neurons display punctate APPL immunoreactivity. Some isolated cells in the brain (Figs. $7 D$ and $8 B$ ) and thoracic ganglion (not shown) show higher levels of APPL expression. As shown previously (Fig. 7D), the lamina is highly stained, and separate processes are detected in the medulla. Interestingly, the highest levels of APPL protein are local- 

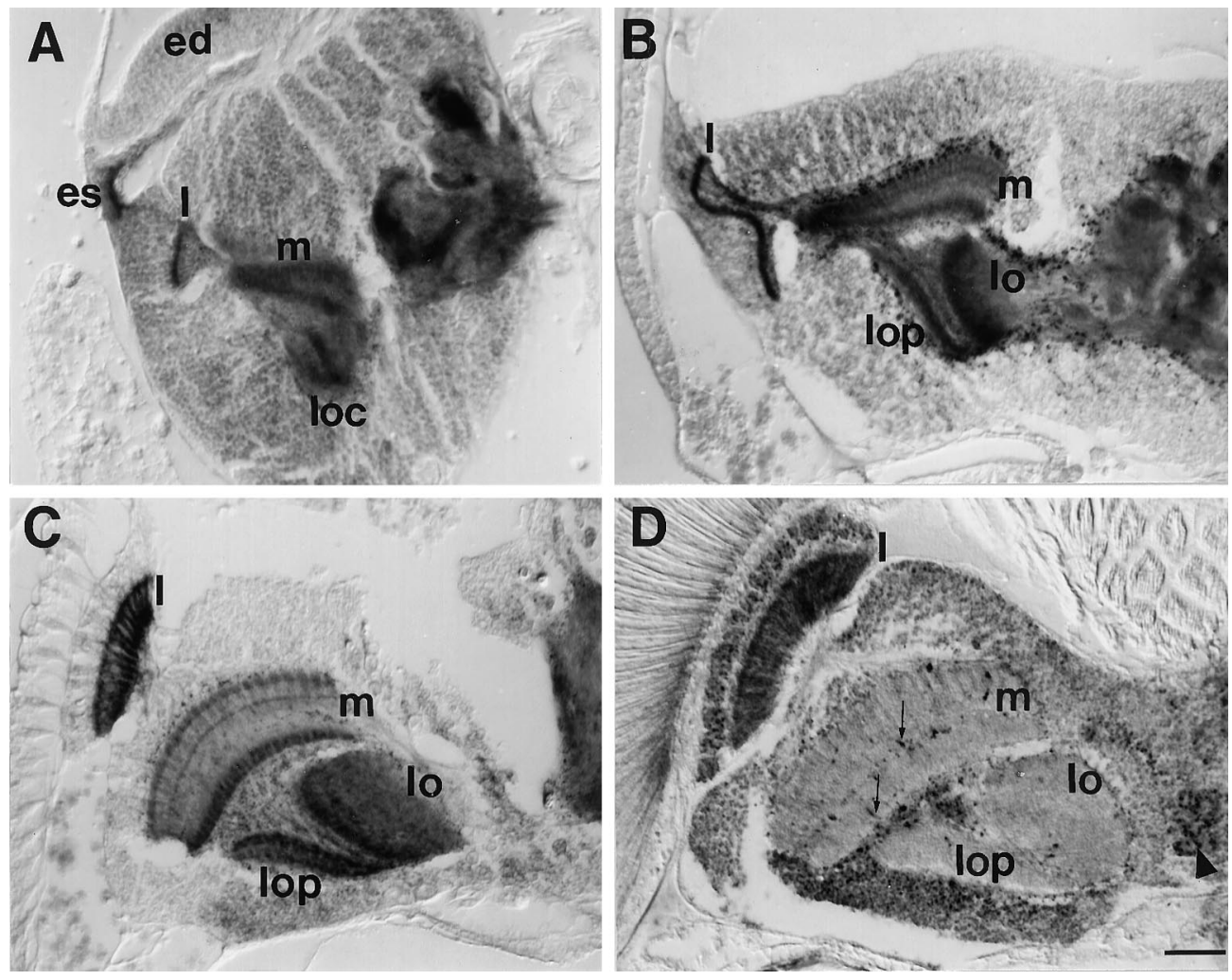

Figure 7. APPL immunoreactivity in the optic lobe during metamorphosis. Horizontal paraffin section of heads of $0 \mathrm{hr}(A), 25 \mathrm{hr}(B)$, and $60 \mathrm{hr}(C)$ pupae and adult $(D)$ stained with anti-APPL antibody. $A, 0$ hr after pupariation, APPL-immunoreactive photoreceptor axons project from the eye disk (ed) through the eye stalk (es) into the optic lobe. The lamina $(l)$, the outer and inner medulla neuropils $(m)$, and the two neuropils in the lobula complex (loc) in the optic lobes are highly stained with APPL. B, By 25 hr after pupariation, APPL immunoreactivity in the medulla neuropil starts to split into three layers, the two outer ones being connected by processes. In the lobula complex, the lobula (lo) and lobula plate (lop) neuropils are intensely stained. $C, 60 \mathrm{hr}$ after pupariation, the optic neuropils have rotated. In the lamina $(l)$, axons are distinguishable. In the medulla $(m)$, APPL is arranged in three layers, showing a columnar organization. $D$, In adult, intense APPL signal remains only in the lamina neuropil $(l)$. In the medulla, isolated processes are APPL-immunoreactive (thin arrows). Some cell bodies show higher APPL immunoreactivity (arrowhead; lamina cortex). For $A-D$, anterior is at the top and lateral at the left. Same magnification was used for all. Scale bar (shown in D): $25 \mu \mathrm{m}$. ized in the neuropil of the mushroom bodies (Fig. 8). Mushroom bodies are a principal site of olfactory information processing and are involved in associative olfactory learning and memory in Drosophila (Heisenberg et al., 1985; for reviews, see Davis, 1993; Heisenberg, 1994). They consist of two complex bilaterally symmetrical groups of neurons (Kenyon cells) in the dorsal-posterior brain that receive input predominantly from the antennal lobes. Kenyon cell dendrites form the calyces, whereas their axons extend through the peduncle to the anterior of the brain. There, these axons form three different neuropils: the $\alpha$ lobe, which extends dorsally, and the $\beta$ and $\gamma$ lobes, which extend medially. Figure 8 illustrates APPL immunoreactivity in the mushroom bodies. All of the mushroom body axonal neuropils are intensely stained, including the peduncle $(p), \alpha$ lobe (Fig. $8 A$ ), and $\beta / \gamma$ lobes (Fig. $8 B$ ). The cell bodies of the Kenyon cells show slightly higher signal than the rest of the cortex. Their dendrites, however, do not appear enriched in APPL protein (Fig. $8 C$ ). APPL protein is also detected in the central complex ( $c c$; Fig. $8 A, B)$, the major structure of Drosophila brain controlling locomotor behavior (Strauss and Heisenberg, 1993) that has been shown to play an important role in learning in Drosophila (Heisenberg et al., 1985; Bouhouche et al., 1993; for review, see Heisenberg, 1994). In the rest of the brain neuropil, some isolated processes are highly stained (Fig. 8A).

The concentration of APPL protein detected in the axonal neuropil of the adult mushroom bodies directed our attention to the distribution of APPL in the larval mushroom bodies. As shown in Figure 9A, APPL is found in the neuropil of the larval mushroom bodies, although the relative amount of protein in these structures, differing from what is observed in the adult brain, is comparable to or even lower than the levels of APPL protein detected in other brain and ventral ganglion neuropil areas. Interestingly, the mutant protein APPL ${ }^{\text {sd }}$ concentrates in the mushroom bodies at much higher levels than the endogenous APPL protein (Fig. 9C), whereas induced wild-type APPL (not shown) and mutant APPL $^{\mathrm{s}}$ (Fig. 9B) protein are detected at very low levels in this structure.

In the adult, although a higher rate of synthesis of APPL protein in the Kenyon cells is suggested by the immunohistochemistry (Fig. $8 B-D$ ), we were interested in examining whether the differential metabolism of APPL protein could account for part of the selective neuropil staining, as seen in larval brain. For APP, it has been shown that cell activity can affect secretion and distribution of the protein (Nitsch et al., 1993, 1994). Using the same rationale applied to the study of APPL localization in larval brains, we analyzed the distribution of APPL protein expressed under a heat-shock promoter in $A p p l^{\mathrm{d}}$; $h s p: A p p l^{+} /+$adult brains. As shown in Figure $8 F, 4 \mathrm{hr}$ after the heat shock, induced wildtype APPL protein is especially concentrated in the axonal neuropil of the mushroom bodies and in the lamina, those areas where endogenous APPL is enriched. As is the case with the endogenous protein, the mushroom body calyces do not show enrichment of induced APPL (Fig. $8 E$ ). Similar to what was observed in larvae, mutant APPL ${ }^{\text {sd }}$ protein induced in adult brains was found enriched in the axonal neuropil of the mushroom bodies and along processes going from the lamina into the medulla (not shown). The staining observed with $\mathrm{APPL}^{\mathrm{s}}$ in adult brains was quite variable. In the mushroom bodies, APPL $^{\mathrm{s}}$ immunoreactivity ranged from no signal to some discernible staining. In no case was enrichment of the signal comparable to wild type observed. Nevertheless the variability in signal precludes any 
Figure 8. APPL immunoreactivity in the adult mushroom bodies. $A-D$, Horizontal paraffin sections of Canton $S$ adult heads stained with APPL antibody. $A$, Dorsal section of a brain showing APPL concentrated in the $\alpha$ lobes $(\alpha)$ and in the peduncle $(p)$. In addition, APPL immunoreactivity is significantly higher in the central complex $(c c)$ and in isolated processes (thin arrows). B, A section illustrating APPL immunoreactivity along the whole peduncle and in the $\beta / \gamma$ lobes. APPL signal is higher in the cell bodies of the Kenyon cells (lower arrowhead) and in isolated neurons throughout the cortex (right arrowhead). $C-D$, Two adjacent paraffin sections showing APPL immunoreactivity absent from the dendritic fields in the calyces (open arrow) but present in axonal neuropils, such as the peduncle $(p)$, and in Kenyon cell bodies (arrowhead). Small arrows in $C$ point to Kenyon axons that converge to form the peduncle. $E-F$, An adult of the genotype $\mathrm{Appl}^{\mathrm{d}}$; $h s p: \mathrm{Appl}^{+} /+$was heat-shocked for $30 \mathrm{~min}$ at $37^{\circ} \mathrm{C}$. After a $4 \mathrm{hr}$ resting period, the head was processed for paraffin sectioning and immunolabeled with anti-APPL antibody as described (see Materials and Methods). Two alternate sections are shown. $E$, Dendrites in the calyx do not show enrichment of APPL protein (open arrow), whereas the Kenyon axons converging to form the peduncle do (small arrows). F, Intense APPL signal is seen in the lamina neuropil $(l)$ and in the peduncle $(p)$ of the mushroom body. For $A-F$, anterior is to the top. Same magnification was used for all. Scale bar (shown in F): $25 \mu \mathrm{m}$.
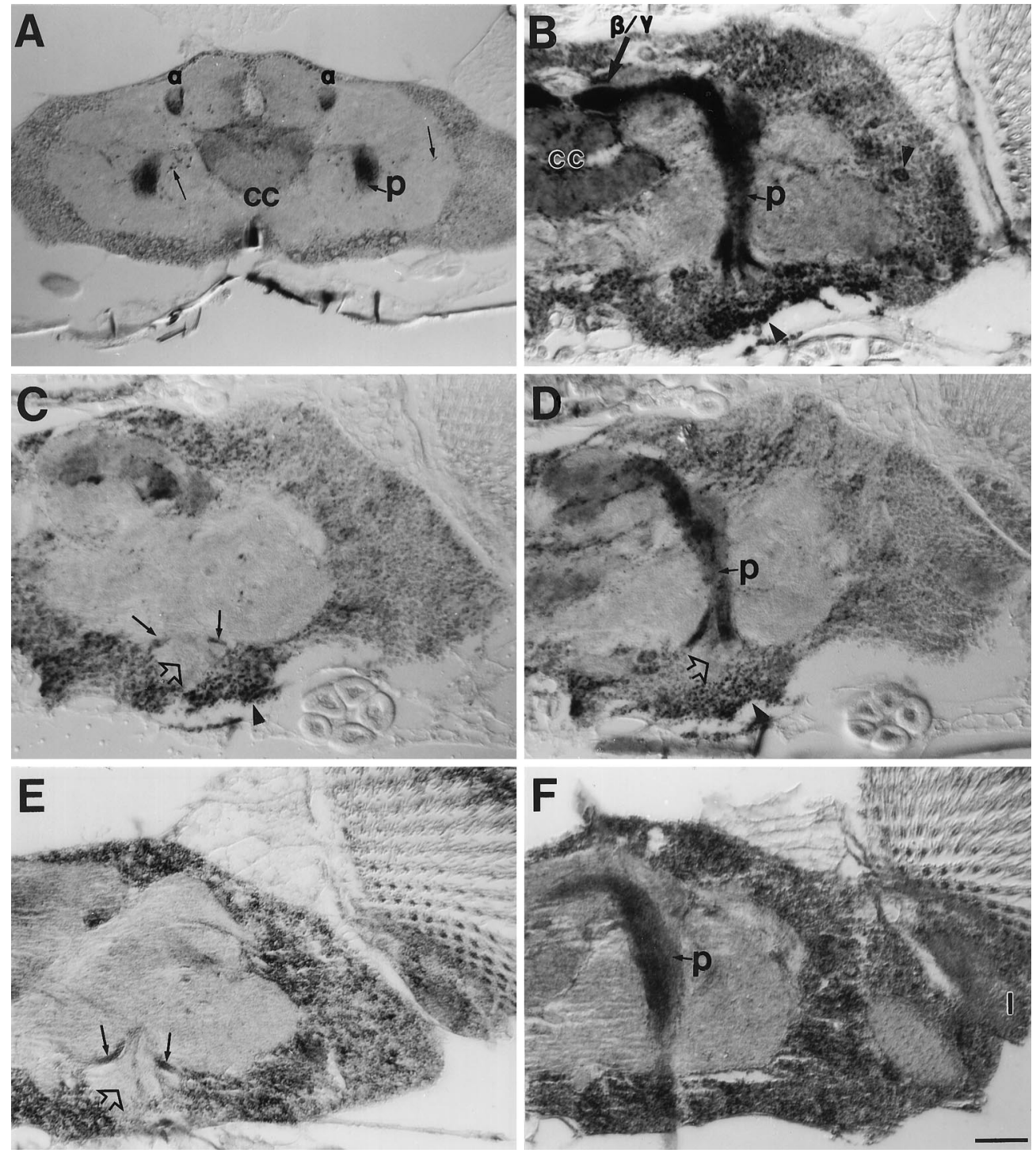

conclusions about the distribution of the APPL ${ }^{\mathrm{s}}$ form in the adult brain.

In the adult, APPL is concentrated in regions known to mediate behavioral plasticity. It is interesting that APPL is found enriched in the axons but not in the dendrites of the Kenyon cells. Moreover, the cell-type specificity of APPL processing and trafficking is involved in generating its differential distribution in the adult neuropil.

\section{DISCUSSION}

In this study, we have performed an immunocytochemical analysis of the distribution of wild-type and mutant APPL proteins in the Drosophila CNS. Rescue experiments of the behavioral defects of $A p p l^{\text {d }}$ flies demonstrated the functional homology between APPL and at least one member of the APP-family (Luo et al., 1992). The advantages of using Drosophila to gain insights into the function of the APP-family of proteins are the following: (1) neurons in different developmental and physiological states can be examined and compared in the same preparation; (2) neuronal soma and processes are delineated spatially so that the relative distribution of the protein in these subcellular compartments can be examined; (3) it is possible to study APPL wild-type and mutant proteins generated by transgenes expressed under heat-shock induction in an Appl-null background; and (4) the $A p p l$ gene is expressed exclusively in the nervous system and seems not to be alternatively spliced. Thus, the Appl gene of Drosophila offers a simpler in vivo situation when compared with the complexities encountered with the APP-family in mammals where three distinct but closely related genes with multiple splicing variants have been identified that show broad and overlapping tissue distribution (Kang et al., 1987; Wasco et al., 1992, 1993; Slunt et al., 1994).

\section{Subcellular localization of APPL proteins}

Because anti-APPL antibody Ab952M recognizes the ectodomain of APPL present in both transmembrane holoprotein and soluble protein, our studies cannot differentiate between the two forms. Therefore, to distinguish between these two forms we have used transgenes that express mutant proteins: $\mathrm{APPL}^{\mathrm{s}}$, which lacks the transmembrane and cytoplasmic domain, and $\mathrm{APPL}^{\mathrm{sd}}$, in which the cleavage site is deleted. We have found that in the neuronal cell body, APPL immunoreactivity is concentrated in punctate structures that resemble the localization of APP in mammalian cells (Kuentzel et al., 1993; Allinquant et al., 1994; Caporaso et al., 

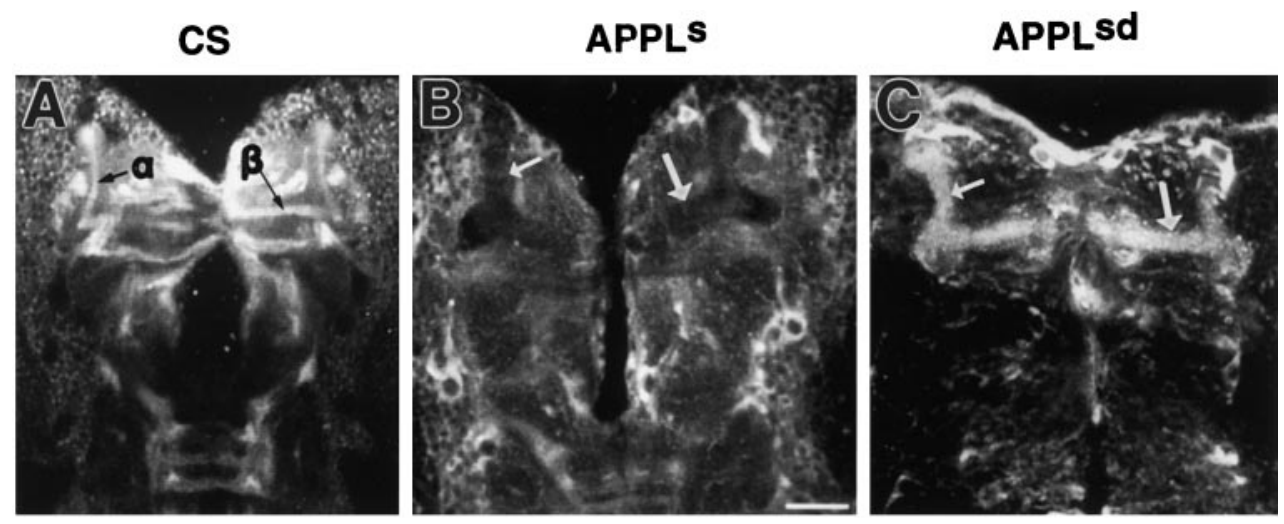

Figure 9. APPL immunoreactivity in the larval mushroom bodies. $A, \mathrm{~A}$ semihorizontal optical section of a wild-type larval CNS, where APPL signal in the neuropil of the mushroom bodies $[\alpha$ (short arrow) and $\beta / \gamma$ (long arrow) lobes] is evidenced. $B-C$, Larval CNSs of genotypes (B) $A p p l^{\mathrm{d}} ; h s p: A p p l^{\mathrm{s}} /+$ and $(C) A p p l^{\mathrm{d}} ; h s p$ : $A p p l^{\mathrm{sd}} /+$ were heat-shocked at $37^{\circ} \mathrm{C}$ for 1 $\mathrm{hr}$, allowed to rest for $4 \mathrm{hr}$, and immunoprocessed with anti-APPL antibody. Semihorizontal optical sections are shown. $B$, $\mathrm{APPL}^{\mathrm{s}}$ protein is not enriched in the neuropil of the larval mushroom bodies. $C$, $\mathrm{APPL}^{\text {sd }}$ protein is highly concentrated in the neuropil of the larval mushroom bodies. For $A-C$, anterior is to the top. Same magnification was used for all. Scale bar (shown in $B$ ): $25 \mu \mathrm{m}$.

1994). Previous experiments have shown that cleavage and secretion of APPL and the mammalian APP-family members are similar (Luo et al., 1990, 1992). Moreover, proteolytic processing of APP through the $\alpha$-secretase pathway is conserved among metazoans, because the protein is processed normally in insect (Ramakrishna et al., 1991; Ramabhadran et al., 1993) and yeast (Hines et al., 1994; Zhang et al., 1994) cells. Thus, APPLimmunoreactive cytoplasmic structures may correspond to at least some of the compartments in which APP has already been found, such as endoplasmic reticulum and Golgi (Palacios et al., 1992; Caporaso et al., 1994).

An intriguing observation is the lack of APPL immunoreactivity at the plasma membrane of neuronal soma. Cell-surface APPL immunoreactivity is not observed even for the transmembrane secretion-defective protein $\mathrm{APPL}^{\mathrm{sd}}$. One possible explanation is that the protein is inserted at the plasma membrane only after being transported to the axons. Intracellular or cell-surface localization of APPL within axons cannot be resolved with the techniques used in this study, but finding APPL immunoreactivity along axonal tracts in flies expressing only the APPL ${ }^{\text {sd }}$ protein is consistent with this interpretation. In addition, in cells with a high rate of cleavage and secretion, the molecules that escape proteolytic processing could be degraded rapidly and thus rarely reach the cell surface. Finally, the presence of an internalization signal sequence in the cytoplasmic domain of APPL suggests that APPL might be internalized in a way similar to that described for APP (Haass et al., 1992; Yamazaki et al., 1995). Recent studies performed on primary cultured neurons suggest that APP holoprotein can cycle rapidly at the plasma membrane (Allinquant et al., 1994; Yamazaki et al., 1995).

In the mushroom bodies, APPL seems to be transported selectively to the axons but not to the dendrites. Our analysis does not address whether this polarized transport is specific to the Kenyon cells or whether it is a general rule. Other neurons, like the sensory neurons of the embryo and larval disks and the antennal sensory neurons of the adult, show normal levels of APPL protein in the soma, but no enrichment in dendrites or axons (data not shown). Thus, polarized transport of APPL might be regulated selectively in different neuronal populations. Similarly, APLP2 is present in both pre- and postsynaptic compartments in the olfactory bulb, but only in postsynaptic sites in hippocampal and cortical neurons (Thinakaran et al., 1995). On the contrary, APLP1 protein has been localized selectively in the postsynaptic densities (Kim et al., 1995), whereas APP has been shown to be transported anterogradely and retrogradely through the axons
(Koo et al., 1990; Sisodia et al., 1993; Yamazaki et al., 1995) and localized in both dendrites and axons (Masliah et al., 1992; Allinquant et al., 1994; Clarris et al., 1995).

\section{Differential trafficking of APPL proteins}

APPL-immunoreactive signal can vary dramatically between different axonal pathways and in different neuropil regions, suggesting that there is differential regulation of APPL metabolism in different neurons. We observed differential APPL signal in the neuropil and axonal tracts even when all cells are synthesizing APPL under the heat-shock promoter, which indicates that selective synthesis alone cannot account for the differential APPL distribution. Our data, based on the degree of association of APPL with axonal markers, suggest that APPL immunoreactivity associated with neuropil regions can be attributed to secreted or transmembrane APPL or both, depending on the region analyzed. A mechanism by which regulated cleavage and trafficking results in the differential distribution of APPL is further suggested by the distribution observed with the secreted APPL ${ }^{\mathrm{s}}$ and secretiondefective APPL ${ }^{\text {sd }}$ mutant proteins. Although the localization of the APPL mutant proteins is consistent with the interpretations of the double-labeling experiments, an artifactual localization of the mutant proteins cannot be excluded.

Recent studies on APP in epithelial cells have revealed two independent mechanisms that operate in the sorting of surface and secreted APP, respectively: (1) polarized secretion of APP that does not require the transmembrane and cytoplasmic domains and (2) polarized sorting of surface APP that depends on signals located in the cytoplasmic domain (De Strooper et al., 1995; Haass et al., 1995). Consistent with this mechanism, $\mathrm{APPL}^{\mathrm{s}}$ protein lacking the cytoplasmic and transmembrane domains accumulates in regions where endogenous APPL accumulates, probably as a secreted form, suggesting that the transmembrane and cytoplasmic domains are not required for polarized transport to axons and secretion of the soluble form. Similarly, the secretiondefective APPL $^{\text {sd }}$ is transported to the axons in certain neuronal populations and is enriched in areas where APPL is found associated with neuronal processes. As for APP (Kuentzel et al., 1993; Haass et al., 1995), experiments in Drosophila tissue culture cells suggest the existence of an intracellular proteolytic pathway for APPL (Luo, 1992; Luo et al., 1990). Therefore, although both transmembrane and soluble APPL forms co-exist in the neuronal soma, the axon may contain only one of the two forms by means of a selective sorting and transport.

We recognize that cleavage of APPL is also likely to be differ- 
entially regulated. For example, a specific mechanism that selectively transports the secreted APPL form to the axons would preclude the presence of the holoprotein in those axons. APPL ${ }^{\text {sd }}$ protein, however, is very often found along axonal commissures in the ventral ganglion, where endogenous APPL is never detected. Other mechanisms, such as differential stabilization and internalization, could also contribute to the pattern of APPL distribution.

\section{Developmental regulation of APPL distribution}

The pattern of distribution of APPL during development indicates that the metabolism of APPL protein is regulated dynamically during neuronal differentiation. Heterogeneities in the state of differentiation of neurons can account for at least part of the differential regulation of APPL metabolism seen in larval brains. It is worth mentioning that the distribution of at least one protein, the receptor tyrosine phosphatase DPTP69D, is strikingly similar to APPL in the neuropil of larval ventral ganglion and optic lobes (Desai et al., 1994). The similar distribution of these two proteins could simply reflect the specific biological properties of those neuropil areas; however, it could also be indicative of a functional relationship between these two proteins.

In the optic lobes of late third-instar larvae, when axonal growth is taking place, transmembrane APPL is the predominant form detected. Later, during the major period of synaptogenesis in the optic neuropils, APPL concentrates in layers that resemble those where synapses are forming. Similarly, transmembrane APP is associated preferentially with the rapid elongation of axons (Moya et al., 1994), whereas high levels of secreted APP have been correlated with the major periods of synaptogenesis (Loffler and Huber, 1992; Moya et al., 1994). The dynamic regulation of APPL metabolism during axonogenesis and synaptogenesis suggests a role for $\mathrm{Appl}$ function in these developmental processes and could account for the behavioral abnormalities observed in flies deficient for the Appl gene (Luo et al., 1992).

\section{Enrichment of APPL in the mushroom bodies}

Finally, in the adult brain, the mushroom bodies show high levels of APPL immunoreactivity. Although not comparable to the levels of protein detected in the mushroom bodies, the central complex also shows enrichment in APPL. These two structures are insect brain centers that are implicated in associative learning and other complex behaviors (Erber et al., 1980; Heisenberg et al., 1985; Bouhouche et al., 1993; for review, see Heisenberg, 1994). Therefore, the requirement of $\mathrm{Appl}$ function in the mature nervous system could also explain the behavioral deficits displayed by Appl-null mutants. The fact that APPL is concentrated in the axon termini, but not in dendritic fields, suggests that the protein is transported to the presynaptic terminals in the Kenyon cells. Experiments with mutant APPL forms indicate that the membrane-bound APPL holoprotein is the most likely form concentrated in the mushroom bodies. In response to stimulation of the Kenyon cells, APPL transport, cleavage, and secretion in the presynaptic site could be regulated, and this regulation might be involved in modification of synaptic contacts between Kenyon cells and their synaptic targets. Factors similar to those that have been implicated in APP secretion and trafficking, e.g., protein kinase C (Buxbaum et al., 1990; Caporaso et al., 1992; Gillespie et al., 1992), extracellular matrix components (Monning et al., 1995), and intracellular levels of calcium (Allinquant et al., 1994), might participate in this regulation.

In summary, by using transgenes expressing normal and mutant
APPL proteins, we have been able to show differential metabolism of APPL in different neuronal cell types. Moreover, processing and trafficking of APPL is regulated dynamically in differentiating neurons. In adult brains, APPL is enriched in centers responsible for behavioral plasticity in insects. The precise regulation of APPL metabolism supports the importance of Appl function in the Drosophila nervous system and suggests that transmembrane and secreted APPL forms are playing distinct roles and that both may be biologically active. The use of Drosophila offers an ideal system to test specific functions for these two forms.

\section{REFERENCES}

Allinquant B, Moya K, Bouillot C, Prochiantz A (1994) Amyloid precursor protein in cortical neurons: coexistence of two pools differentially distributed in axons and dendrites and association with cytoskeleton. J Neurosci 14:6842-6854.

Barger SW, Fiscus RR, Ruth P, Hofmann F, Mattson MP (1995) Role of cyclic GMP in the regulation of neuronal calcium and survival by secreted forms of $\beta$-amyloid precursor. J Neurochem 6416:2087-2096.

Bausenwein B, Fischbach KF (1992) Activity labeling patterns in the medulla of Drosophila melanogaster caused by motion stimuli. Cell Tissue Res 270:25-35.

Bausenwein B, Dittrich AP, Fischbach KF (1992) The optic lobe of Drosophila melanogaster. II. Sorting of retinotopic pathways in the medulla. Cell Tissue Res 267:17-28.

Bonner JJ, Pardue ML (1976) The effect of heat shock on RNA synthesis in Drosophila tissues. Cell 8:43-50.

Bouhouche A, Vaysse G, Corbière M (1993) Immunocytochemical and learning studies of a Drosophila melanogaster neurological mutant, nobridge ${ }^{\mathrm{ks} 49}$, as an approach to the possible role of the central complex. J Neurogenet 9:105-121.

Buxbaum J, Gandy S, Cicchetti P, Ehrlich M, Czernik A, Fracasso R, Ramabhadran T, Unterbeck A, Greengard P (1990) Processing of Alzheimer $\beta \mathrm{A} 4$ amyloid precursor protein: modulation by agents that regulate protein phosphorylation. Proc Natl Acad Sci USA 87:6003-6006.

Caporaso GL, Gandy SE, Buxbaum JD, Ramabhadran TV, Greengard P (1992) Protein phosphorylation regulates secretion of Alzheimer beta/A4 amyloid precursor protein. Proc Natl Acad Sci USA 89:3055-3059.

Caporaso GL, Takei K, Gandy SE, Matteoli M, Mundigl O, Greengard P, De Camilli P (1994) Morphologic and biochemical analysis of the intracellular trafficking of the Alzheimer $\beta / \mathrm{A} 4$ amyloid precursor protein. J Neurosci 14:3122-3138.

Clarris HJ, Key B, Beyreuther K, Masters CL, Small DH (1995) Expression of the amyloid protein precursor of Alzheimer's disease in the developing rat olfactory system. Dev Brain Res 88:87-95.

Daigle I, Li C (1993) apl-1, a Caenorhabditis elegans gene encoding a protein related to the human beta-amyloid protein precursor. Proc Natl Acad Sci USA 90:12045-12049.

Davis RL (1993) Mushroom bodies and Drosophila learning. Neuron 11:1-14.

Desai CJ, Popova E, Zinn K (1994) A Drosophila receptor tyrosine phosphatase expressed in the embryonic CNS and larval optic lobes is a member of the set of proteins bearing the "HRP" carbohydrate epitope. J Neurosci 14:7272-7283.

De Strooper B, Craessaerts K, Dewachter I, Moechars D, Greenberg B, Leuven FV, Berghe HV (1995) Basolateral secretion of amyloid precursor protein in Madin-Darby canine kidney cells is disturbed by alterations of intracellular $\mathrm{pH}$ and by introducing a mutation associated with familial Alzheimer's disease. J Biol Chem 270:4058-4065.

Erber J, Masuhr TH, Menzel R (1980) Localization of the short term memory in the brain of the bee Apis mellifera. Physiol Entomol 5:343-358.

Fujita SC, Zipursky SL, Benzer S, Ferrus A, Shotwell SL (1982) Monoclonal antibodies against the Drosophila nervous system. Proc Natl Acad Sci USA 79:7929-7933.

Furukawa K, Barger SW, Blalock EM, Mattson MP (1996) Activation of $\mathrm{K}^{+}$channels and suppression of neuronal activity by secreted $\beta$-amyloid-precursor protein. Nature 379:74-78.

Gillespie SL, Golde TE, Younkin SG (1992) Secretory processing of the Alzheimer amyloid beta/A4 protein precursor is increased by protein phosphorylation. Biochem Biophys Res Commun 187:1285-1290. 
Haass C, Koo EH, Mellon A, Hung AY, Selkoe DJ (1992) Targeting of cell surface $\beta$-amyloid precursor protein to lysosomes: alternative processing into amyloid-bearing fragments. Nature 357:500-503.

Haass C, Koo EH, Capell A, Teplow D, Selkoe DJ (1995) Polarized sorting of $\beta$-amyloid precursor protein and its proteolytic products in MDCK cells is regulated by two independent signals. J Cell Biol 128:537-547.

Harlow E, Lane D (1988) Antibodies: a laboratory manual. Cold Spring Harbor, NY: Cold Spring Harbor Laboratory.

Heisenberg M (1994) Central brain functions in insects: genetic studies on the mushroom bodies and central complex in Drosophila. In: Neural basis of behavioral adaptations (Rathmayer W, ed), pp 30-39. New York: Gustav Fischer Verlag.

Heisenberg M, Borst A, Wagner S, Byers D (1985) Drosophila mushroom body mutants are deficient in olfactory learning. J Neurogenet $2: 1-30$.

Hines V, Zhang W, Ramakrishna N, Styles J, Mehta P, Kim KS, Innis M, Miller DL (1994) The expression and processing of human betaamyloid peptide precursors in Saccharomyces cerevisiae: evidence for a novel endopeptidase in the yeast secretory system. Cell Mol Biol Res 40:273-284.

Jin L, Ninomiya H, Roch J, Schubert D, Masliah E, Otero DA, Saitoh T (1994) Peptides containing the RERMS sequence of amyloid $\beta / \mathrm{A} 4$ protein precursor bind cell surface and promote neurite extension. J Neurosci 14:5461-5470.

Kang J, Lemaire HG, Unterbeck A, Salbaum JM, Masters CL, Grzeschik KH, Multhaup G, Beyreuther K, Müller-Hill B (1987) The precursor of Alzheimer's disease amyloid A4 protein resembles a cell-surface receptor. Nature 325:733-736.

Kim T, Wu K, Xu J, McAuliffe G, Tanzi RE, Wasco W, Black IB (1995) Selective localization of amyloid precursor-like protein 1 in the cerebral cortex postsynaptic density. Mol Brain Res 32:36-44.

Koo EH, Sisodia SS, Archer DA, Martin LJ, Weidemann A, Beureuther P, Fisher C, Masters CL, Price DL (1990) Precursor of amyloid protein in Alzheimer's disease undergoes fast anterograde axonal transport. Proc Natl Acad Sci USA 87:1561-1565.

Kuentzel SL, Ali SM, Altman RA, Greenberg BD, Raub TJ (1993) The Alzheimer $\beta$-amyloid protein precursor/protease nexin-II is cleaved by secretase in a trans-Golgi secretory compartment in human neuroglioma cells. Biochem J 295:367-378.

Lis JT, Simon JA, Sutton CA (1983) New heat shock puffs and $\beta$-galactosidase activity resulting from transformation of Drosophila with an hsp70-lacZ hybrid gene. Cell 35:403-410.

Littleton JT, Bellen HJ, Perin MS (1993) Expression of synaptotagmin in Drosophila reveals transport and localization of synaptic vesicles to the synapse. Development 118:1077-1088.

Loffler J, Huber G (1992) Beta-amyloid precursor protein isoforms in various rat brain regions and during brain development. J Neurochem 59:1316-1324.

Luo L (1992) Functional analysis of APPL, the Drosophila homologue of human amyloid precursor protein associated with Alzheimer's disease. Waltham, MA: Brandeis.

Luo L, Martin-Morris LE, White K (1990) Identification, secretion, and neural expression of APPL, a Drosophila protein similar to human amyloid protein precursor. J Neurosci 10:3849-3861.

Luo L, Tully T, White K (1992) Human amyloid precursor protein ameliorates the behavioral deficits of flies deleted for Appl gene. Neuron 9:595-605.

Luo L, Liao YJ, Jan LY, Jan YN (1994) Distinct morphogenetic functions of similar small GTPases: Drosophila Drac1 is involved in axonal outgrowth and myoblast fusion. Genes Dev 8:1787-1802.

Martin-Morris LE, White K (1990) The Drosophila transcript encoded by the $\beta$-amyloid protein precursor-like gene is restricted to the nervous system. Development 110:185-195.

Masliah E, Mallory M, Ge N, Saitoh T (1992) Amyloid precursor protein is localized in growing neurites of neonatal rat brain. Brain Res 593:323-328.

Meinertzhagen IA, Hanson TE (1993) The development of the optic lobe. In: The development of Drosophila melanogaster (Bate M, Martinez Arias A, eds), pp 1363-1491. Cold Spring Harbor, NY: Cold Spring Harbor Laboratory.

Milward EA, Papadopoulos R, Fuller SJ, Moir RD, Small D, Beyreuther K, Masters CL (1992) The amyloid protein precursor of Alzheimer's disease is a mediator of the effects of nerve growth factor on neurite outgrowth. Neuron 9:129-137.
Monning U, Sandbrink R, Weidemann A, Banati RB, Masters CL, Beyreuther K (1995) Extracellular matrix influences the biogenesis of amyloid precursor protein in microglial cells. J Biol Chem 270:7104-7110.

Moya KL, Benowitz LI, Schneider GE, Allinquant B (1994) The amyloid precursor protein is developmentally regulated and correlated with synaptogenesis. Dev Biol 161:597-603.

Müller U, Cristina N, Li Z, Wolfer DP, Lipp H, Rülicke T, Brandner S, Aguzzi A, Weissmann C (1994) Behavioral and anatomical deficits in mice homozygous for a modified $\beta$-amyloid precursor protein gene. Cell 79:755-765.

Nishimoto I, Okamoto T, Maysuura S, Okamoto T, Murayama Y, Ogata E (1993) Alzheimer amyloid protein precursor complexes with brain GTP-binding protein $\mathrm{G}_{0}$. Nature 362:75-79.

Nitsch RM, Farber SA, Growdon JH, Wurtman RJ (1993) Release of amyloid beta-protein precursor derivatives by electrical depolarization of rat hippocampal slices. Proc Natl Acad Sci USA 90:5191-5193.

Nitsch RM, Slack BE, Farber SA, Schulz JG, Deng M, Kim C, Borghesani PR, Korver W, Wurtman RJ, Growdon JH (1994) Regulation of proteolytic processing of the amyloid beta-protein precursor of Alzheimer's disease in transfected cell lines and in brain slices. J Neural Transm [Suppl] 44:21-27.

Okado H, Okamoto H (1992) A Xenopus homologue of the human beta-amyloid precursor protein: developmental regulation of its gene expression. Biochem Biophys Res Commun 189:1561-1568.

Okamoto T, Takeda S, Murayama Y, Ogata E, Nishimoto I (1995) Ligand-dependent $\mathrm{G}$ protein coupling function of amyloid transmembrane precursor. J Biol Chem 270:4205-4208.

Palacios G, Palacios JM, Mengod G, Frey P (1992) Beta-amyloid precursor protein localization in the Golgi apparatus in neurons and oligodendrocytes: an immunocytochemical structural and ultrastructural study in normal and axotomized neurons. Brain Res Mol Brain Res 15:195-206.

Patel NH, Snow PM, Goodman CS (1987) Characterization and cloning of fasciclin III: a glycoprotein expressed on a subset of neurons and axon pathways in Drosophila. Cell 48:975-988.

Pirrotta V (1988) Vectors for P-mediated transformations in Drosophila. In: Vectors: a survey of molecular cloning vectors and their uses (Rodriguez RL, Reinhardt DT, eds), pp 437-456. Boston: Butterworths.

Ramabhadran TV, Gandy SE, Ghiso J, Czernik AJ, Ferris D, Bhasin R, Goldgaber D, Frangione B, Greengard P (1993) Proteolytic processing of human amyloid beta protein precursor in insect cells: major carboxylterminal fragment is identical to its human counterpart. J Biol Chem 268:2009-2012.

Ramakrishna N, Saikumar P, Potempska A, Wisniewski HM, Miller DL (1991) Expression of human Alzheimer amyloid precursor protein in insect cells. Biochem Biophys Res Commun 174:983-989.

Rosen RR, Martin-Morris L, Luo L, White K (1989) A Drosophila gene encoding a protein resembling the human $\beta$-amyloid protein precursor. Proc Natl Acad Sci USA 86:2478-2482.

Sambrook J, Fritsch EF, Maniatis T (1989) Molecular cloning: a laboratory manual. Cold Spring Harbor, NY: Cold Spring Harbor Laboratory.

Sherriff FE, Bridges LR, Jackson P (1994) Microwave antigen retrieval of $\beta$-amyloid precursor protein immunoreactivity. Clin Neurosci Neuropathol 5:1085-1088.

Sisodia SS, Koo EH, Hoffman PN, Perry G, Price DL (1993) Identification and transport of full-length amyloid precursor protein in rat peripheral nervous system. J Neurosci 13:3136-3142.

Sisodia SS, Slunt HH, Van Koch C, Lo ACY, Thinakaran G (1994) Studies on APP biology: analysis of APP secretion and characterization of an APP homologue, APLP2. In: Amyloid protein precursor in development, aging and Alzheimer's disease (Masters CL, Beyreuther K, Trillet M, Christen Y, eds), pp 121-133. New York: Springer.

Slunt HH, Thinakaran G, Koch CV, Lo AC, Tanzi RE, Sisodia SS (1994) Expression of a ubiquitous, cross-reactive homologue of the mouse beta-amyloid precursor protein (APP). J Biol Chem 269:2637-2644.

Spradling AC, Rubin GM (1982) Genetic transformation of Drosophila with transposable element vectors. Science 218:348-353.

Strauss R, Heisenberg M (1993) A higher control center of locomotor behavior in the Drosophila brain. J Neurosci 13:1852-1861.

Thinakaran G, Kitt CA, Roskams JI, Slunt HH, Masliah E, von Koch C, Ginsberg SD, Ronnett GV, Reed RR, Price DL, Sisodia SS (1995) 
Distribution of an APP homologue, APLP2, in the mouse olfactory system: a potential role for APLP2 in axogenesis. $J$ Neurosci 15:6314-6326.

Truman J, Taylor BJ, Awad TA (1993) Formation of the adult nervous system. In: The development of Drosophila melanogaster (Bate M, Martinez Arias A, eds), pp 1245-1275. Cold Spring Harbor, NY: Cold Spring Harbor Laboratory.

Wasco W, Bupp K, Magendantz M, Gusella JF, Tanzi RE, Solomon F (1992) Identification of a mouse brain cDNA that encodes a protein related to the Alzheimer disease-associated amyloid $\beta$ protein precursor. Proc Natl Acad Sci USA 89:10785-10762.

Wasco W, Gurubhagavatula S, Paradis MD, Romano DM, Sisodia SS, Hyman BT, Neve RL, Tanzi RE (1993) Isolation and characterization of the human APLP2 gene encoding a homologue of the Alzheimer's associated amyloid $\beta$ protein precursor. Nature Genet 5:95-100.
Weidemann A, Konig G, Bunke D, Fischer P, Salbaum JM, Masters CL, Beyreuther K (1989) Identification, biogenesis, and localization of precursors of Alzheimer's disease A4 amyloid protein. Cell 57:115-126.

Yamazaki T, Selkoe DJ, Koo EH (1995) Trafficking of cell surface $\beta$-amyloid precursor protein: retrograde and transcytotic transport in cultured neurons. J Cell Biol 129:431-442.

Zhang H, Komano H, Fuller RS, Gandy SE, Frail DE (1994) Proteolytic processing and secretion of human beta-amyloid precursor protein in yeast: evidence for a yeast secretase activity. J Biol Chem 269:27799-27802.

Zheng H, Jiang M, Trumbauer ME, Sirinathsinghji DJ, Hopkins R, Smith DW, Heavens RP, Dawson GR, Boyce S, Conner MW, Stevens KA, Slunt HH, Sisodia SS, Chen HY, Van der Ploeg LHT (1995) betaAmyloid precursor protein-deficient mice show reactive gliosis and decreased locomotor activity. Cell 81:525-531. 